University of Baghdad

College of Engineering

(U)

JOURNAL OF ENGINEERING

\section{Journal of Engineering}

journal homepage: $\underline{w w w . j o e . u o b a g h d a d . e d u . i q ~}$

Number 12 Volume 24 December 2018

Electrical, Electronics and communications, and Computer Engineering

Comparative Analysis of Various Multicarrier Modulation Techniques for Different Multilevel Converters

\author{
Omar Talal Mahmood Altaee* \\ Lecturer \\ Dept. of Electrical Techniques, Technical Institute - \\ Mosul, Northern Technical University \\ Mosul, Iraq \\ omar_taee2002@yahoo.com \\ omar.talal@ntu.edu.iq
}

\author{
Ahmed M. T. Ibraheem Alnaib \\ Lecturer \\ Dept. of Electrical Power Techniques Eng., Technical Eng. \\ College - Mosul, Northern Technical University \\ Mosul, Iraq \\ ahmed_alnaib85@yahoo.com
}

\begin{abstract}
The applications of Multilevel Converter (MLC) are increased because of the huge demand for clean power; especially these types of converters are compatible with the renewable energy sources. In addition, these new types of converters have the capability of high voltage and high power operation. A Nine-level converter in three modes of implementation; Diode ClampedMLC (DC-MLC), Capacitor Clamped-MLC (CC-MLC), and the Modular Structured-MLC (MSMLC) are analyzed and simulated in this paper. Various types of Multicarrier Modulation Techniques (MMTs) (Level shifted (LS), and Phase shifted (PS)) are used for operating the proposed Nine level - MLCs. Matlab/Simulink environment is used for the simulation, extracting, and analysis the results. Finally, a comparison is made between the results for all topologies that are implemented regarding to the criteria of the output voltage waveforms harmonic distortion factor, No. of the necessitated power components, and the complexity of each circuit. Based on simulation results, the MS-MLC is finer as compared to the other types of MLCs. It also observed that the MLCs (with three types) using Phase Opposition Disposition (POD) technique is performed better in terms of getting greater fundamental output voltage and lower THD\% as compared to the other techniques.
\end{abstract}

Keywords: MLC, MMTs, LS, and PS.

*Corresponding author

Peer review under the responsibility of University of Baghdad.

https://doi.org/10.31026/j.eng.2018.12.05

2520-3339 @ 2018 University of Baghdad. Production and hosting by Journal of Engineering.

This is an open access article under the CC BY-NC license http://creativecommons.org/licenses/by-cc-nc/4.0/).

Article received: $2 / 7 / 2017$

Article accepted: $2 / 7 / 2018$ 


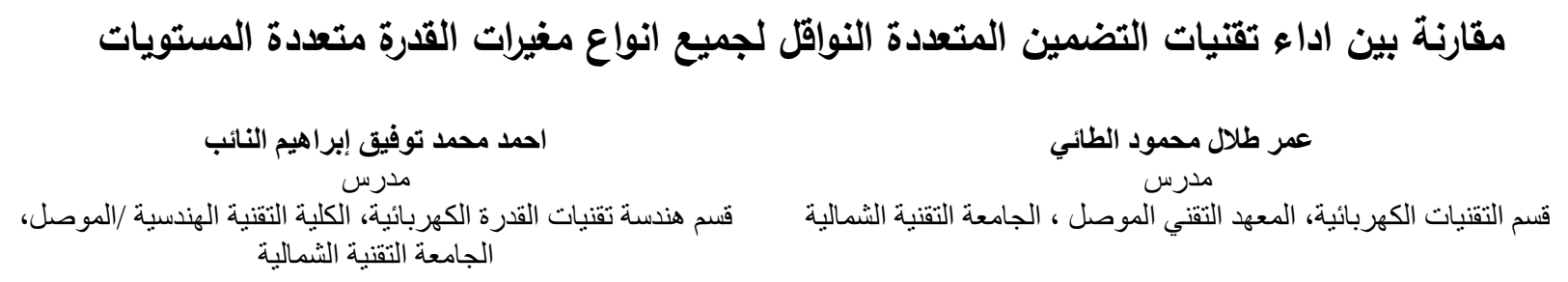

الخلاصة

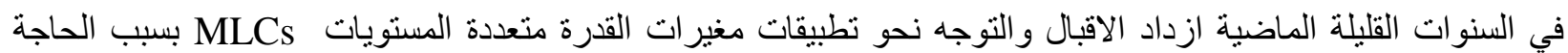

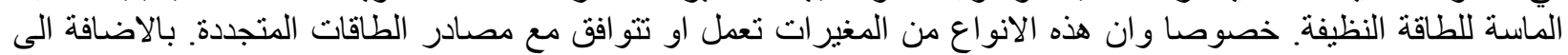

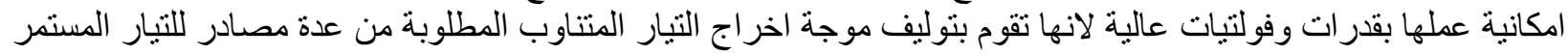

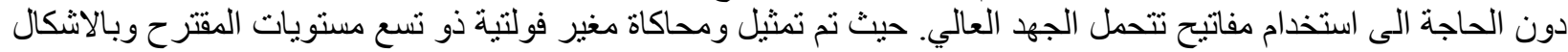

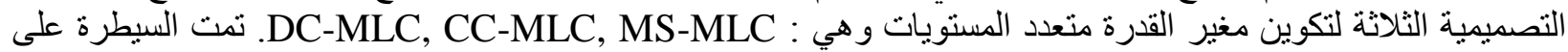

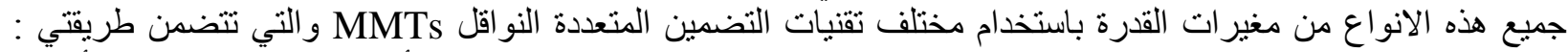

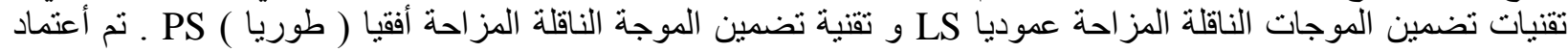

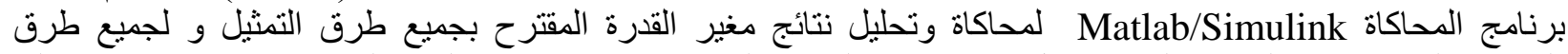

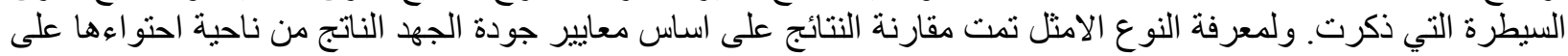

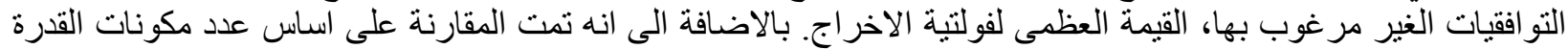

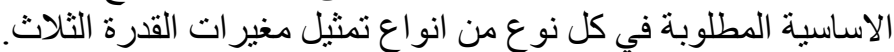

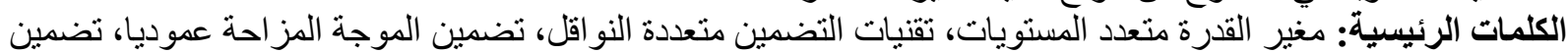
الموجة المز احة أفقيا.

\section{INTRODUCTION}

The necessity to work switching power converters in huge power usage has forced the advancement of multilevel conversion arrangements. This is acutely for the reason that ability of MLCs to operate at high voltages and then to synthesize as waveforms of excellent spectral quality. The development of MLC technology has conformed two parallel lanes, the first treating with the converter topologies themselves, and the another dealing with the enhancement of modulation control strategies suitable for the emerging topologies, McGrath, and Holmes, 2012 and this paper deals seriously with these two parallel paths. Numerous modulation controller strategies are used for operating the MLCs. They can generally be classified into three categories as in Kouro, et al., 2008, Manimala, et al., 2011, and Calais, et al., 2001: Selective Harmonic Elimination (SHE) which synthesize the ac voltage by utilizing pre-evaluated switching angles with fundamental switching frequency, Space Vector Strategies (SVS) which have been applied to 3-phase MLC applications, and MMTs or can be known as "Carrier-based modulation techniques", which are a very accepted method in industrial usages. This paper focuses on all types of topology for MLC, unlike the researchers of Venka, et al., 2014, Dubey, et al., 2016 whereas the researchers focus on MS-MLCs, while authors Rane, et al., 2014 simulate only DCMLC topology, and finally in Thielemans, et al., 2009, the researcher focuses on CC-MLC. Our work involves an analysis and simulation of nine-level MLC (in three types of topology) with all types of MMTs. A complete comparison between them regarding to the criteria of output voltage quality (fundamental peak voltage, Total Harmonic Distortion (THDV) of the output voltage) has been done. In addition to the comparison of the number of the power component requirements per phase leg among three MLCs.

\section{MULTILEVEL CONVERTER TOPOLOGIES}

The MLCs are basically classified into three forms in its structure. All the topologies have the similar property of dropping the harmonics. MLCs have many attractive features ( Compared 
with common two level converters) that is: ability of working with high voltage, reduced common mode voltages, lower switching voltage stress, upgrades the output voltage waveform, and smaller or even no output filter is required. The limitation of the MLC is that it required a great amount of semiconductors component, Kouro, et al., 2008, Aswini, et al., 2017.

\subsection{Diode Clamped Multilevel Converter}

This type of converter uses single dc voltage source that is partitioned into a numeral of voltage steps by the chain sequence of capacitors known as "dc side capacitors". The purpose of clamping diodes in the circuit is to avoid the voltage through one of the switching power devices which exceed the voltage across one of the capacitors, Rane, et al., 2014, and Seyezhai, et al., 2008. The output voltage of an L-level MLC equivalent to the following equation

$L=2 L^{\prime}-1$

Where: $L^{\prime}$ is the number of the levels of the output voltage per phase leg.

As in this work the 9-level (line voltage converter (L)), has a 5-levels (per phase level converter $\left.\left(\mathrm{L}^{\prime}\right)\right)$.

To produce L'-level staircase output phase voltage: Common ( $\left.L^{\prime}-1\right)$ dc side capacitors are needed, $\left(\mathrm{L}^{\prime}-1\right) *\left(\mathrm{~L}^{\prime}-2\right)$ clamping diodes it should be used, $2 *\left(\mathrm{~L}^{\prime}-1\right)$ main switching devices are needed for each phase leg. Thus three of dc side capacitors ( $\mathrm{C} 1, \mathrm{C} 2$, and C3), six of clamping diodes in each phase leg, and six of power switch and its parallel diodes are used in the structure of a 7-level DC-MLC ( $\mathrm{L}^{\prime}=4$ ) is shown in Fig. 1-a, Nami, et al., 2008.

\subsection{Capacitor Clamped Multilevel Converter}

This converter is identical to DC-MLC in their structure, excepting of using clamping capacitors in place of clamping diodes as shown in Fig. 1- b; circuit diagram of a seven-level ( $\left.\mathrm{L}^{\prime}=4\right) \mathrm{CC}$ MLC. To generate L'- level staircase output phase voltage: (L' - 1) dc link capacitors are needed. $\left(L^{\prime}-1\right) *\left(L^{\prime}-2\right) / 2$ clamping capacitors are required for each phase leg $\left(\right.$ as $\mathrm{C}_{\mathrm{a} 1}, \mathrm{C}_{\mathrm{a} 2}$, and $\left.\mathrm{C}_{\mathrm{a} 3}\right)$. Each phase leg of the converter should contains of $2 *\left(L^{\prime}-1\right)$ main switching devices and its parallel diodes. The major problem of these types of converters is that it requires most number of capacitor comparative to other MLC, causing to arise difficulties of the packaging and huge weight, Thielemans, et al., 2009.

\subsection{Modular Structured Multilevel Converter}

This type includes a chain of $\mathrm{H}$ - Bridge converter modules. The main concept of this type of converters is to synthesize the required ac output voltage from numerous separate dc input sources, Manimala, et al., 2011. The MS-MLC is well appropriate for renewable energy applications because naturally of offering isolated dc sources: as Photovoltaic (PV), Aswini, et al., 2017, rectified output of Wind turbine generator as in paper of Samue, et al., 2010, Fuel Cell, Seyezhai, et al., 2008, in addition to in some paper a hybrid renewable power sources were used for MLC as a hybrid (PV plus Wind) as in research of Ganesh, et al., 2014.

The number of levels varies with the number of $\mathrm{H}$ - Bridge Module (M) which is equal to the number of dc source $\left(E_{M}\right)$, the expression can be written as $(L=2 M+1)$. So, the number of $L$ can be easily controlled by attaching or eliminating the M, as shown below in Fig. 2, Zainal, et al., 2009, and Charai, et al., 2017.

MS-MLC owns several distinctions over other MLC topologies in terms of circuit arrangement flexibility, and casing is possible because each level reiterated with the same structure. Furthermore, it does not suffer the voltage-unbalancing problem as experienced by the DC-MLC 
(its average) and in CC-MLC (it's high). MS-MLC is more convenient than other MLC because it doesn't have any clamping diode and clamping capacitor, Aswini, et al., 2017.

\section{MULTICARRIER MODULATION TECHNIQUES}

The power electronic switches of MLC are mainly controlled with MMTs. MMTs can be divided into two types: LS- Pulse Duration Modulation (PDM) methods, where several carriers are level (Vertically) shifted, and PS-PDM method, where several carriers are phase (Horizontally) shifted accordingly see Fig. 3, Calais, et al., 2001, and Venka, et al., 2014.

\subsection{Level Shifted Techniques ( Carriers Shifted Vertically )}

This type is also called "Carrier Disposition (CD) techniques". For an $L$ - level converter, $L-1$ carriers with identical frequency and identical peak to peak amplitude are arranged such that the groups they occupy are adjacent. Unique reference waveform is needed and it is put in the center of the carrier set. The reference is always equated with all of the carrier signals. If the reference is greater than the carrier signal, the active device that corresponds to that carrier is switched on and vice versa, Malathy and Ali, 2012. LS-PDM can be categorized into three groups: Phase Disposition (PD), POD, and Alternative Phase Opposition Disposition (APOD) Reddy, et al., 2010, and Angulo, et al., 2007:

\subsubsection{Phase Disposition}

All carriers are in phase as appeared in Fig. 3-a. For this method, major harmonic power is focused at the carrier frequency.

\subsubsection{Phase Opposition Disposition}

All carriers higher than the zero reference value are out of phase with those lower the zero reference value by $180^{\circ}$ as shown in Fig. 3-b.

\subsubsection{Alternative Phase Opposition Disposition}

All the carriers are replacement in position ( i.e. "each carrier is level shifted by $180^{\circ}$ from its next carriers" ) as shown in Fig. 3-c. For this technique, the greatest harmonics are sidebands centered on the carrier frequency with negative harmonics occurring directly on the carrier frequency.

\subsection{Phase Shifted Technique ( Carriers Shifted Horizontally )}

Normally, PS-PWM is used with MS-MLCs and CC-MLCs. In this technique $(L-1) / 2$ carriers are used for a $L-$ level converter, all carriers with same magnitude and frequency but phase shifted by $180^{\circ} /((L-1) / 2)$. There are two of the opposite reference signals (phase shifted by $180^{\circ}$ to each other) are required for the two phase legs of the MLC converter, one for a half leg and the inverted signal for the other half leg as shown in Fig. 3. The gate signals are a result of the comparison between carrier wave and reference signal, McGrath, and Holmes, 2012.

\section{SIMULATION CIRCUITS}

To verify the proposed schemes, a simulation model for nine-level converters is implemented using Matlab/Simulink simulation tool as shown in Fig. 4. MOSFET is chosen as the main power switch for all types of MLCs. Simulation parameters of the proposed MLCs are shown in Table 1. To make a compression between the three circuit diagrams of 9-level MLCs in criteria 
of complexity, Table 2 lists the summary of the needed number of the power electronic element to implements theses circuits.

For all the configurations of MMTs, simulations are done by varying the ( subsystem 1 ) as shown in Fig. 5 which presents a simulation circuit of LS-PDM technique ( PD method ); for implementing the LS-PDM for nine-level MLC, eight carrier signals with the same peak to peak and same switching frequency are required. These eight signals are compared with single reference sine wave to produce eight signals for the first leg of the converters and then are negated to produce the second eight signals for the second leg of the converters.

Fig. 6 shows simulation circuit of PS-PDM technique; four of carrier signals are required to implement this technique then a single carrier signal is used and phase shifted three times with $45^{\circ}$ by using ( three of Transport Delay block ) to produce the another three carrier signals.

\section{SIMULATION RESULTS}

The output voltage and its Harmonic Spectrum (HS) with various MMTs of nine-MLC are shown in the Figures below as following:

Fig.7 shows the results of DC-MLC, Fig. 8 shows the results of CC-MLC, and Fig. 9 shows the results of MS-MLC.

The PS-PDM technique isn't suitable with DC-MLC, where the THD amplitude is very high therefore it is not implemented in the study .

After presenting the output voltage waveforms and its HS of the converters, we make a summary table of the peak amplitude of the fundamental output voltage, and its THD\% of nine-level MLCs for every MMT for easily compression among them, as listed in Table 3.

From Table 3 we conclude that the output of MLCs with POD technique (in each one of three types of MLCs ) has a lower amplitude of THD\% as compared with the other techniques of LSPDM ( PD, and APOD ) and PS-PDM .

It is also seen that MS-MLC with MMTs is better since it provides relatively superior fundamental output voltage and minimal output $\mathrm{THD}_{\mathrm{V}} \%$ compared with the others MLCs types. In addition to the MS-MLC requires the minimum number of power electronic components as compared with two other kinds to achieve the same output voltage levels as shown in Table 2 .

The alone drawback of MS-MLC, it's demanded separately dc sources, but this drawback can be considered as an advantage as its utilization of a great number of dc sources allows for the converter to generate high voltages and thus high power ratings.

\section{CONCLUSIONS}

Nine-level MLC with three types (DC, CC, and MS ) employing different MMTs has been implemented and analyzed. It can be concluded from the results above the following points :

- The harmonics in the output voltage waveform was reduced significantly by applying the different configuration of MMTs especially LS-PDM techniques and as a result there is no need to a high necessity filters .

- In all topologies of MLCs, the harmonic content is proportionate with the numbers of level of the converter, so it's possible to improvement the harmonic content by increasing the levels of the converter. 


\section{REFRENCES}

- Angulo M., Lezana P., Kouro S., Rodriguez J., and Angulo B. W., 2007, Level-Shifted PDM for Cascaded MLCs with even Power Distribution, Power Electronics Specialists IEEE Conference, PP. 2373 - 2378.

- Aswini K., Nandhini K., Nandhini S.R., 2017, Simulation and Analysis of ASCAD Multilevel Inverter with SPWM for Photovoltaic System, International Journal of Innovative Studies in Sciences and Engineering Technology, Vol. 3, Issue 4, PP. 1 - 9.

- Calais M., Borle L.J., and Agelidis V.G. , 2001, Analysis of Multicarrier Methods for a Single-Phase Five Level Converter, 32 ${ }^{\text {nd }}$ IEEE Annual Power Electronics Specialist Conference, Vol. 3, PP. 1351 - 1356.

- Charai M., Raihani A., Bouattan O., Naanani H., 2017, Performance Evaluation for Different Levels MLC Application for Renewable Energy Resources, Journal of Engineering Technology, Vol. 6, Issue 1, PP. 90 - 96.

- Dubey A., Bansal A. k., 2016,Cascade H-bridge Multilevel Inverter at Different Modulation Index, International Journal of Scientific and Research Publications, Vol. 6, Issue 8, PP. 139 -145 .

- Ganesh P., Daiva M, and Arund B., 2014, A Renewable Hybrid Wind Solar Energy System Fed Single Phase MLC, International Journal of Engineering Research \& Technology, Vol. 3, Issue 1, PP. 1615 - 1621.

- Kouro A., Lezana P., Angulo M., and Rodriguez J É, 2008, Multicarrier PDM with DC-Link Ripple Feed-forward Compensation for MLCs, IEEE Transactions on Power Electronics, Vol. 23, No. 1, PP. 52 - 59.

- Malathy S., and Ali U. S., 2012, Performance Analysis of Multi-Carrier PDM Based Cascaded Multilevel Converter, P \& A. Sc and Tech. Journal, PP. 32 - 40.

- Manimala V., Geetha N., and Renuga P., 2011, Design and Simulation of Five Level Cascaded Converter using Multilevel PDM Strategies, $3^{\text {rd }}$ IEEE International Conference on Electronics Computer Technology, Vol. 2, PP. 280 - 283.

- McGrath B. P., and Holmes D. G., 2012, PDM of Multilevel Converters in the Overmodulation Region, $33^{\text {rd }}$ IEEE Annual Power Electronics Specialist Conference, Vol. 2, PP. 485 - 490.

- Nami A., Zare F., Ledwich G., Ghosh A., and Blaabjerg F., 2008, Comparison between Symmetrical and Asymmetrical Single Phase MLC with Diode-Clamped Topology, 39 ${ }^{\text {th }}$ IEEE Annual Power Electronics Specialists Conference, PP. 2921 - 2926.

- Rane B., Gaurav T., and Gaigowal S. R., 2014, Multicarrier Modulation for New Diode Clamped Multilevel Inverter, International Conference on Industrial Automation, PP. 17 22.

- Reddy V. N., Narasimhulu V., Babu D. C., 2010, Control of Cascaded MLC by Using Carrier Based PDM Technique and Implemented, ICGST-ACSE Journal, Vol. 10, Issue 1, PP. 11- 18. 
- Samue P., Nalamati C., and Gupta R., 2010, Wind Energy Conversion based on Seven-level Cascaded H-bridge Inverter using Lab VIEW, International IEEE Conference on Power, Control, and Embedded Systems, PP. 1 - 6.

- Seyezhai R., and Mathur B.L., 2008, Hybrid Cascaded H-Bridge Multilevel Inverter for Fuel Cell Power Conditioning Systems, 43 ${ }^{\text {rd }}$ IEEE International Universities Power Engineering Conference, PP. 1 - 5.

- Thielemans S., Ruderman A., Melkebeek J.A., 2009, Flying Capacitor Multilevel Converter Voltage Balance Dynamics for Pure Resistive Load, $8^{\text {th }}$ IEEE International Symposium on Advanced Electromechanical Motion Systems \& Electric Drives Joint Symposium, PP.1 - 6.

- Venka A., Somanatham R., and Reddy M. S., 2014, Phase Shifted and Level Shifted PWM Based Cascaded Multilevel Inverter, International Journal of Current Engineering and Technology, Vol.4, No.1, PP. 350 - 354.

- Zainal S., and Aziz J., 2009, Derivation of Switching Angles of the Cascaded Multilevel VSC Subjected to a New Pulse Width Modulation Scheme, The Institution of Engineers Journal, Malaysia, Vol. 72, No. 3, PP. 46 - 55.

\section{LIST OF SYMBOLS}

\begin{tabular}{|l|}
\hline APOD $=$ Alternative Phase Disposition \\
\hline CC-MLC = Capacitor Clamped-Multilevel Converter \\
\hline CD $=$ Carrier Disposition \\
\hline DC-MLC = Diode Clamped-Multilevel Converter \\
\hline HS = Harmonic Spectrum \\
\hline LS = Level shifted \\
\hline MLC = Multilevel Converter \\
\hline MMTs = Multicarrier Modulation Techniques \\
\hline MS-MLC = Modular Structured -Multilevel Converter \\
\hline PD = Phase Disposition \\
\hline PDM = Pulse Duration Modulation \\
\hline POD = Phase Opposition Disposition \\
\hline PS = Phase shifted \\
\hline PV = Photovoltaic \\
\hline SHE = Selective Harmonic Elimination \\
\hline SVS = Space Vector Strategy \\
\hline THD = Total Harmonic Distortion \\
\hline
\end{tabular}

Table 1. Simulation parameters.

\begin{tabular}{|c|c|}
\hline Parameters & Value \\
\hline dc voltage source & $100 \mathrm{~V}$ \\
\hline Switching frequency & $5 \mathrm{KHz}$ \\
\hline Fundamental frequency & $50 \mathrm{~Hz}$ \\
\hline$R$ load & $100 \Omega$ \\
\hline$L$ load & $20 \mathrm{mH}$ \\
\hline
\end{tabular}


Table 2. Major element requirements for 9-level MLC types per phase leg.

\begin{tabular}{|c|c|c|c|}
\hline Type of MLC & DC & CC & MS \\
\hline Main power switches & 8 & 8 & 8 \\
\hline Main diodes ( Parallel Diodes ) & 8 & 8 & 8 \\
\hline Clamping diodes & 12 & - & - \\
\hline Clamping capacitors & - & 6 & - \\
\hline dc - link capacitors & 4 & 4 & 0 \\
\hline No. of dc source & 1 & 1 & 4 \\
\hline
\end{tabular}

Table 3. Comparison of Vpeak, and THDv\% for various MMTs for three types of MLC.

\begin{tabular}{|c|c|c|c|c|}
\hline Type of MLC & \multicolumn{2}{|c|}{ Type of MMTs } & $\begin{array}{l}\text { Fundamental } \\
\text { Voltage ( V ) }\end{array}$ & THDv\% \\
\hline \multirow{3}{*}{ DC-MLC } & \multirow{3}{*}{ LS-PDM } & PD & 398.4 & 13.88 \\
\hline & & POD & 398.7 & 13.85 \\
\hline & & APOD & 398.4 & 13.91 \\
\hline \multirow{4}{*}{ CC-MLC } & \multirow{3}{*}{ LS-PDM } & PD & 398.4 & 13.92 \\
\hline & & POD & 398.6 & 13.89 \\
\hline & & APOD & 398.3 & 13.95 \\
\hline & \multicolumn{2}{|c|}{ PS-PDM } & 395 & 14.98 \\
\hline \multirow{4}{*}{ MS-MLC } & \multirow{3}{*}{ LS-PDM } & PD & 399.7 & 13.80 \\
\hline & & POD & 399.9 & 13.77 \\
\hline & & APOD & 399.6 & 13.84 \\
\hline & \multicolumn{2}{|c|}{ PS -PDM } & 395 & 14.98 \\
\hline
\end{tabular}

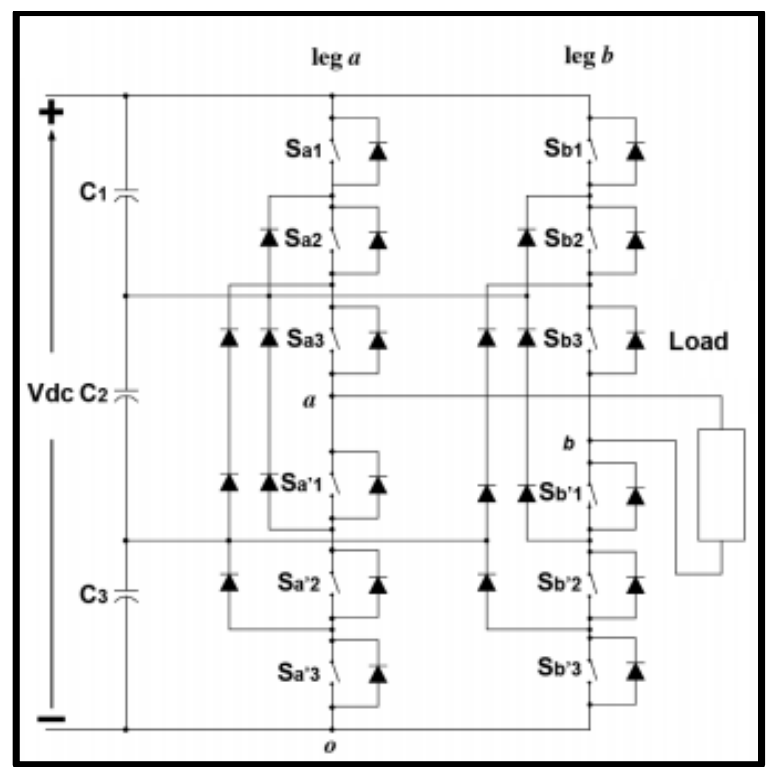

(a) DC-MLC

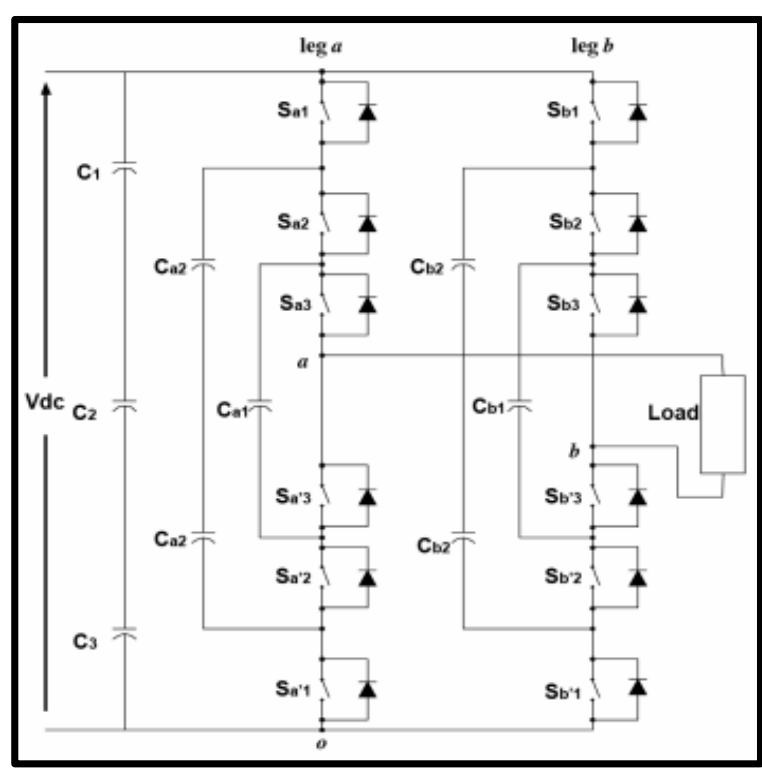

(b) CC-MLC

Figure 1. Circuit diagram of seven-level MLC. 


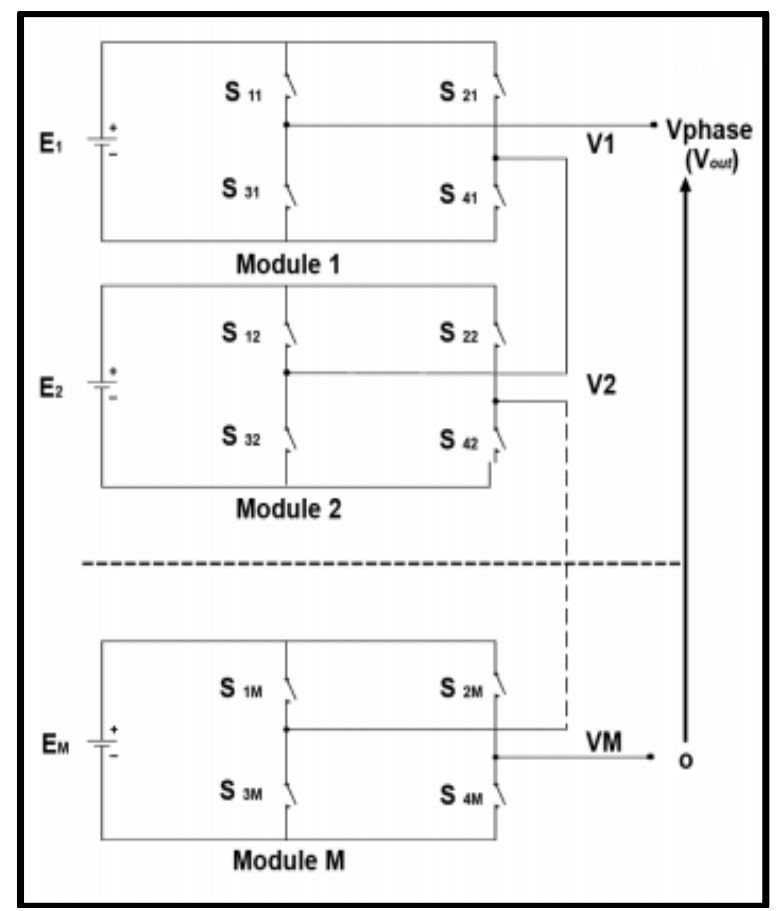

Figure 2. Circuit diagram of MS-MLC.

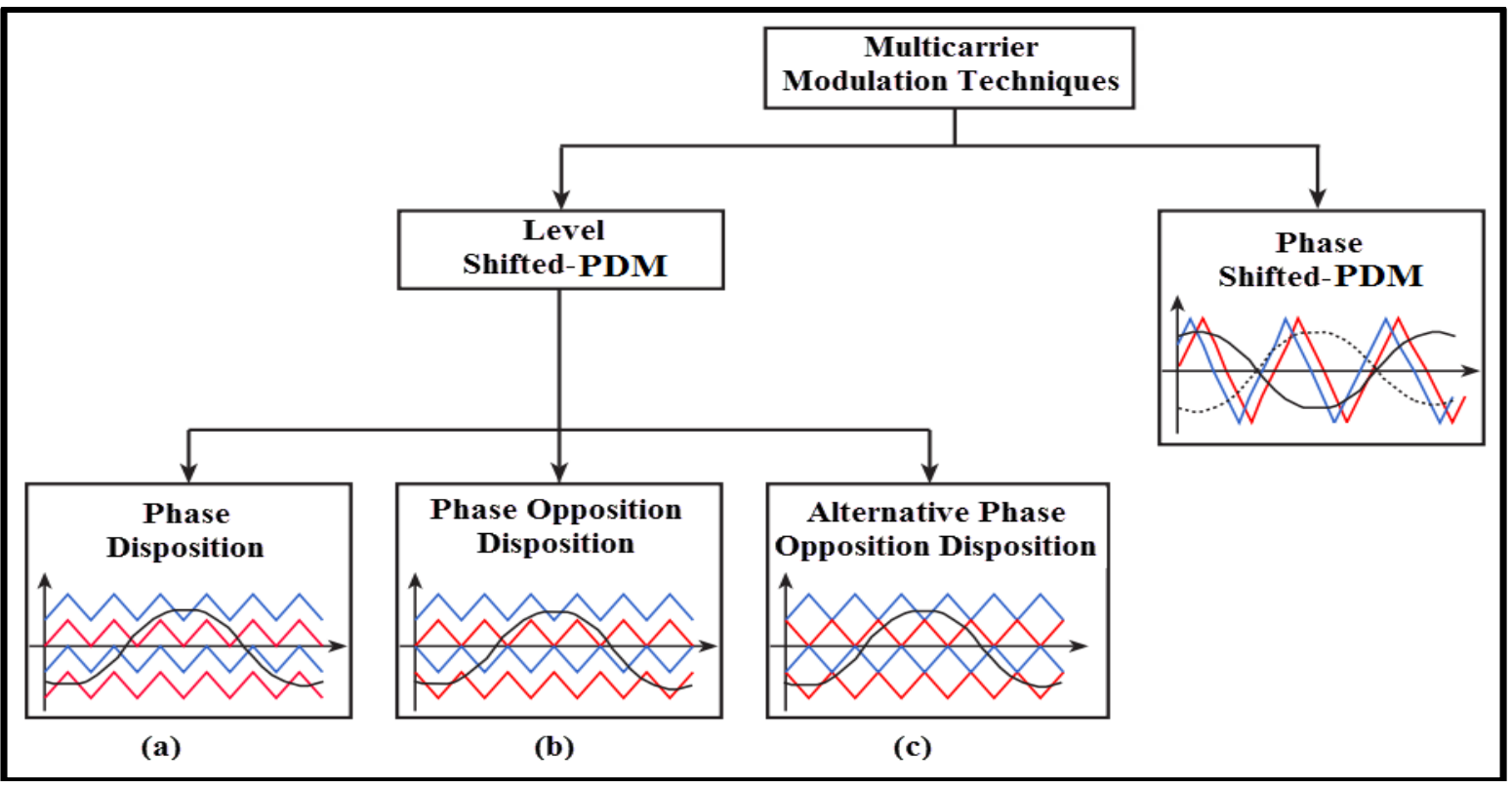

Figure 3. MMTs for MLC. 


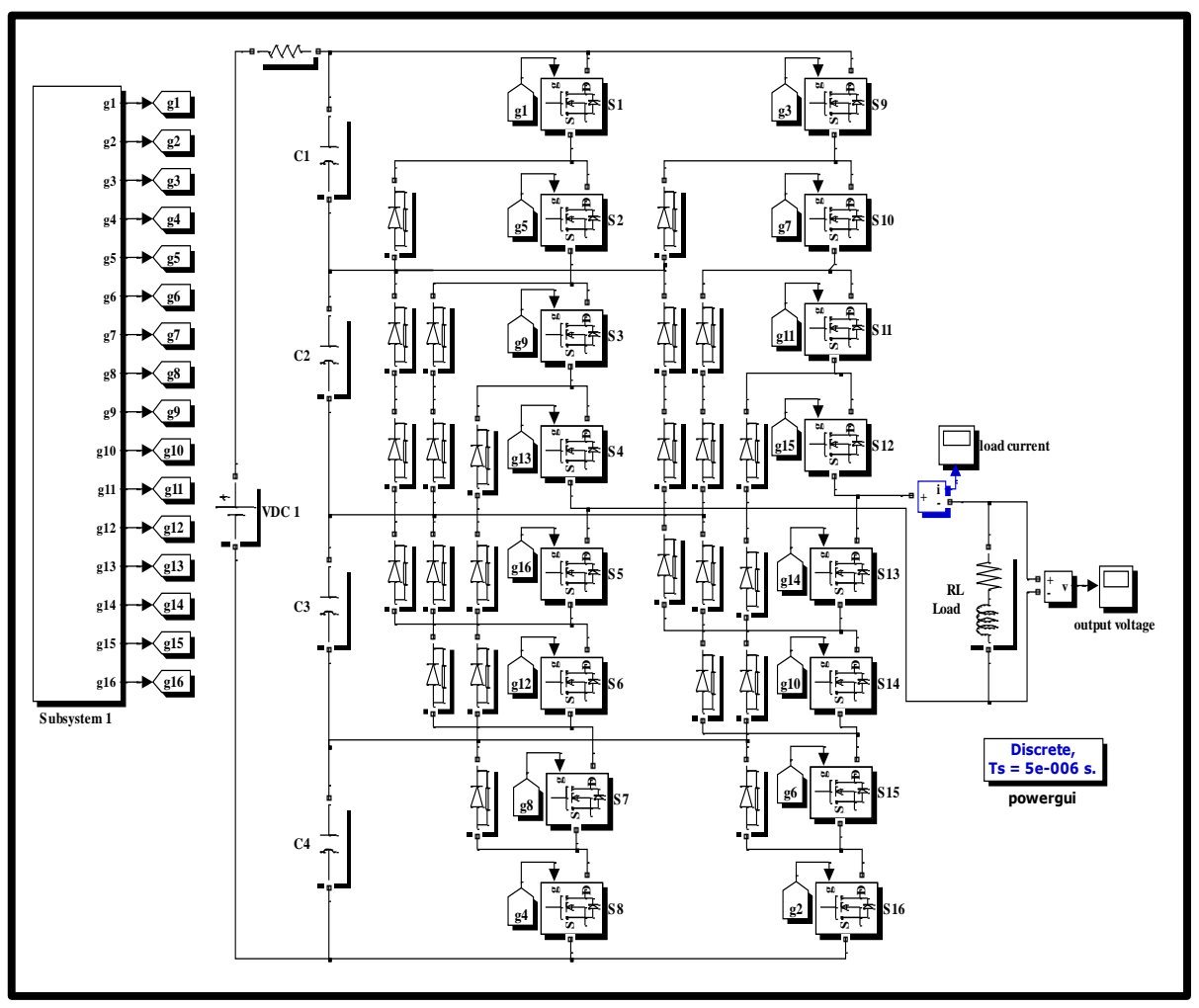

(a) DC-MLC.

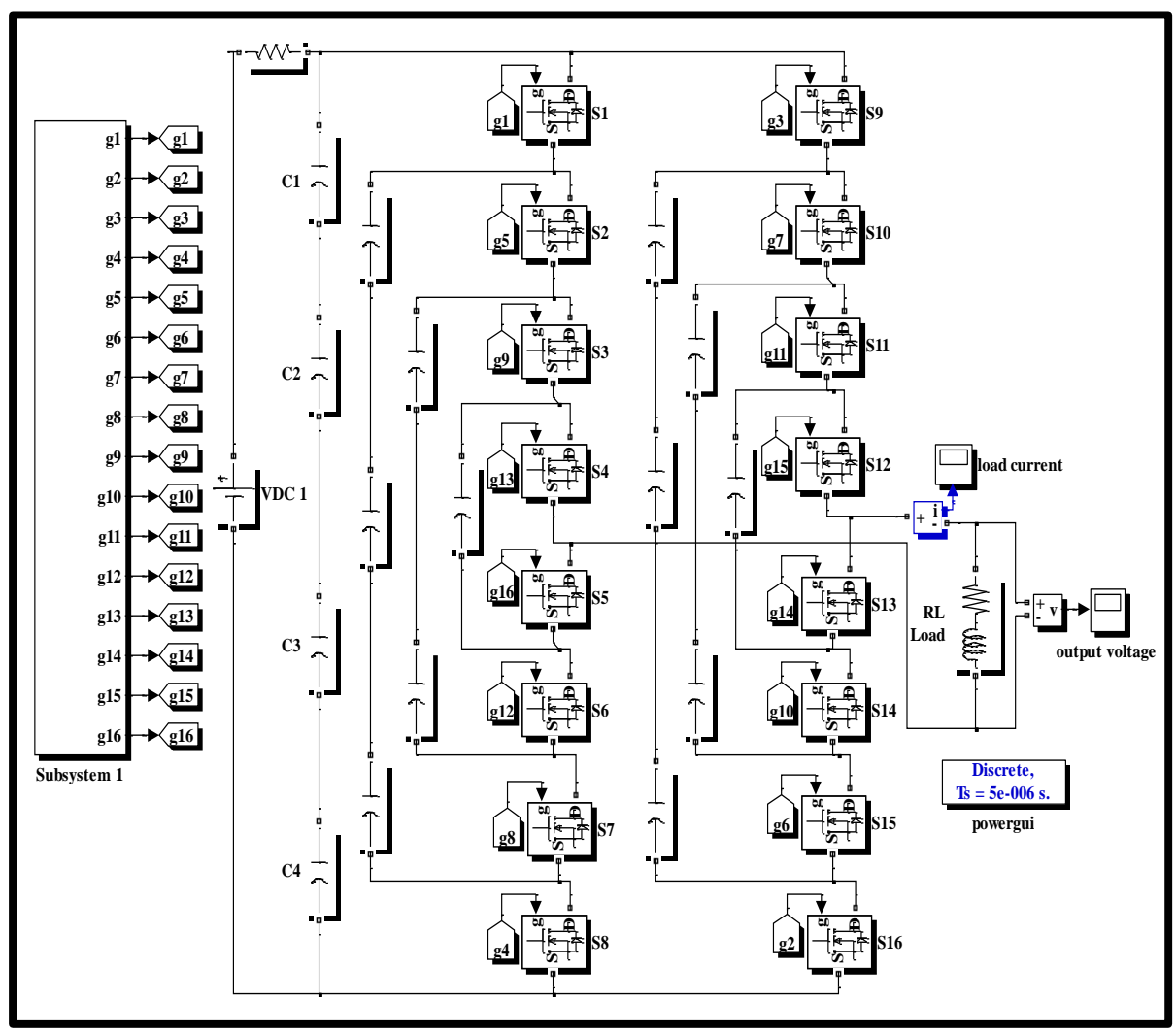

(b) CC-MLC. 


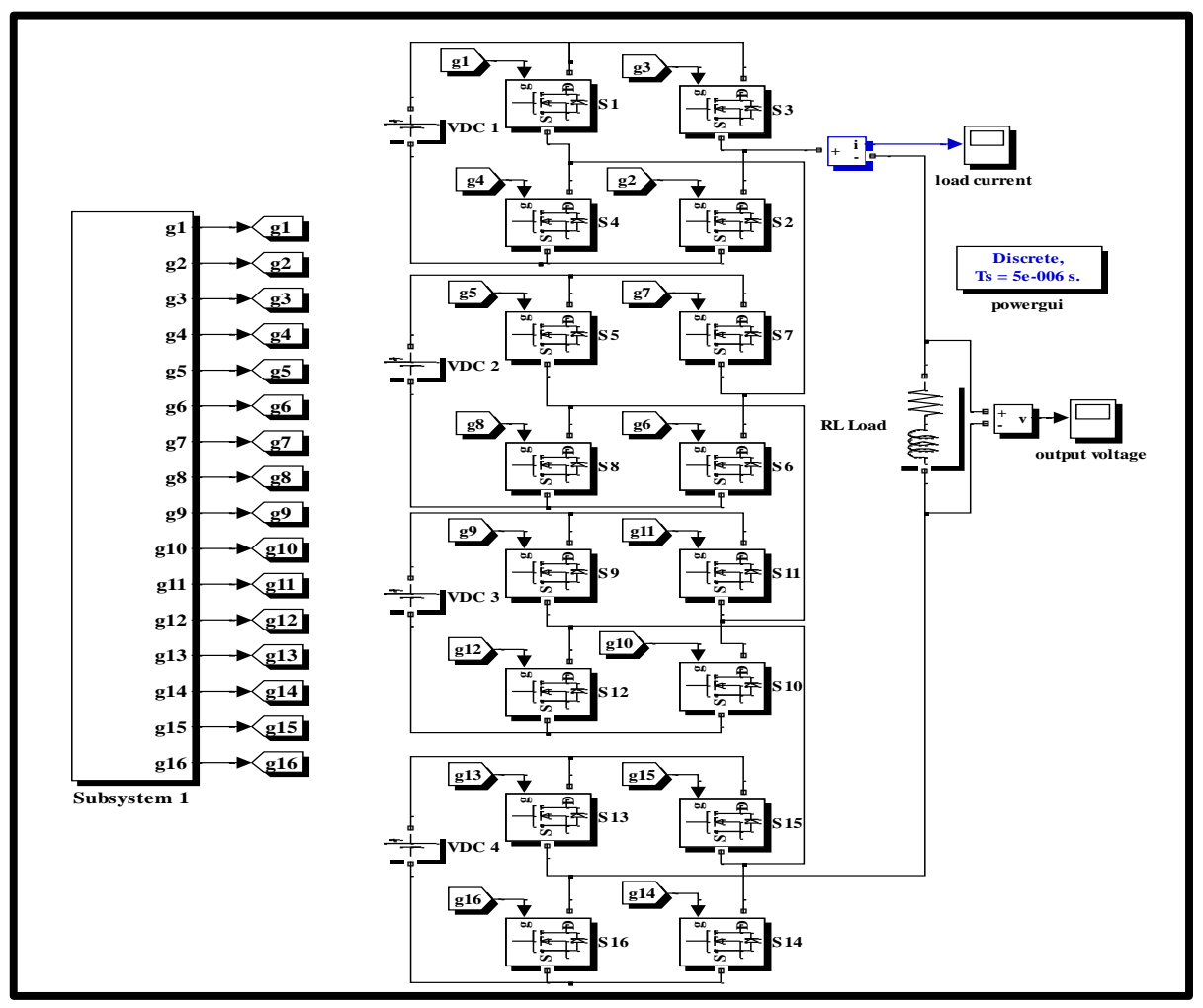

(c) MS-MLC.

Figure 4. Simulation circuits of nine-level: (a) DC-MLC, (b) CC-MLC, and (c) MS-MLC. 
Number 12 Volume 24 December 2018 Journal of Engineering

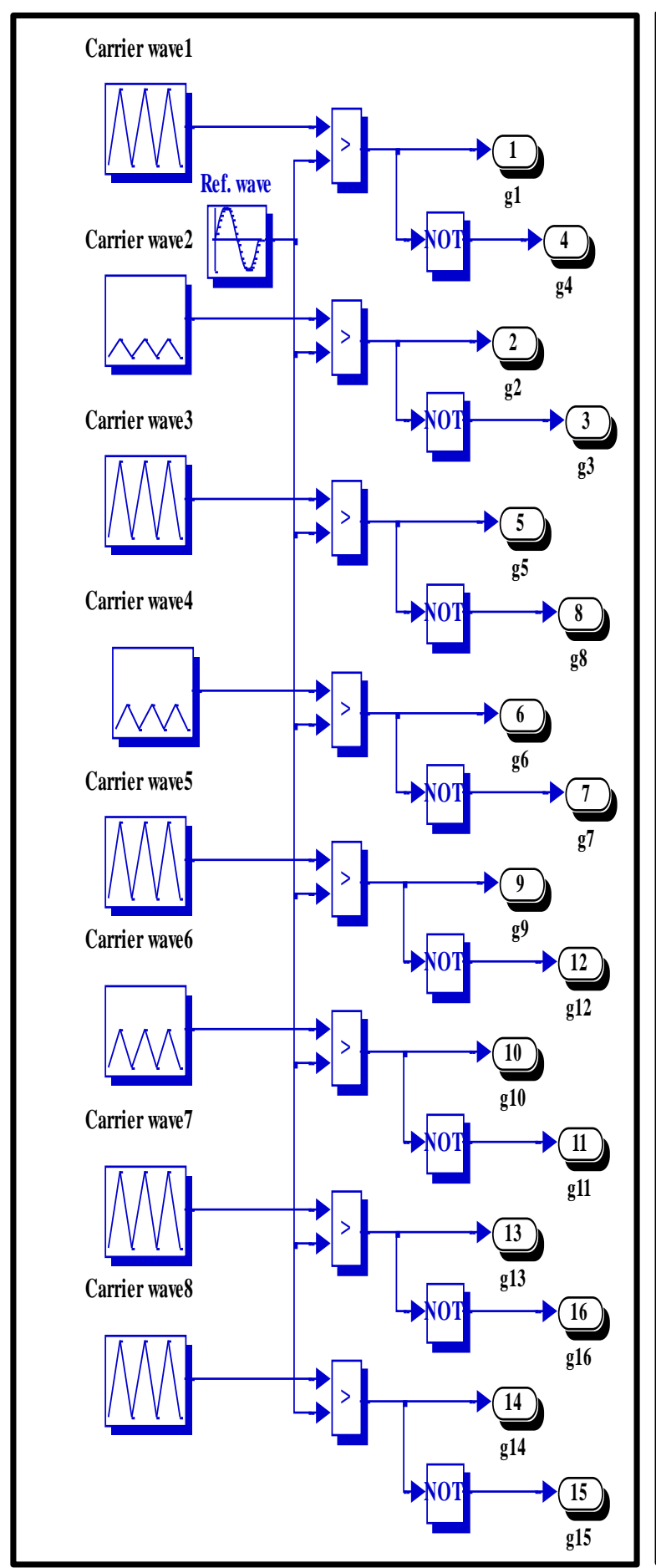

Figure 5. LS-PDM technique (PD).

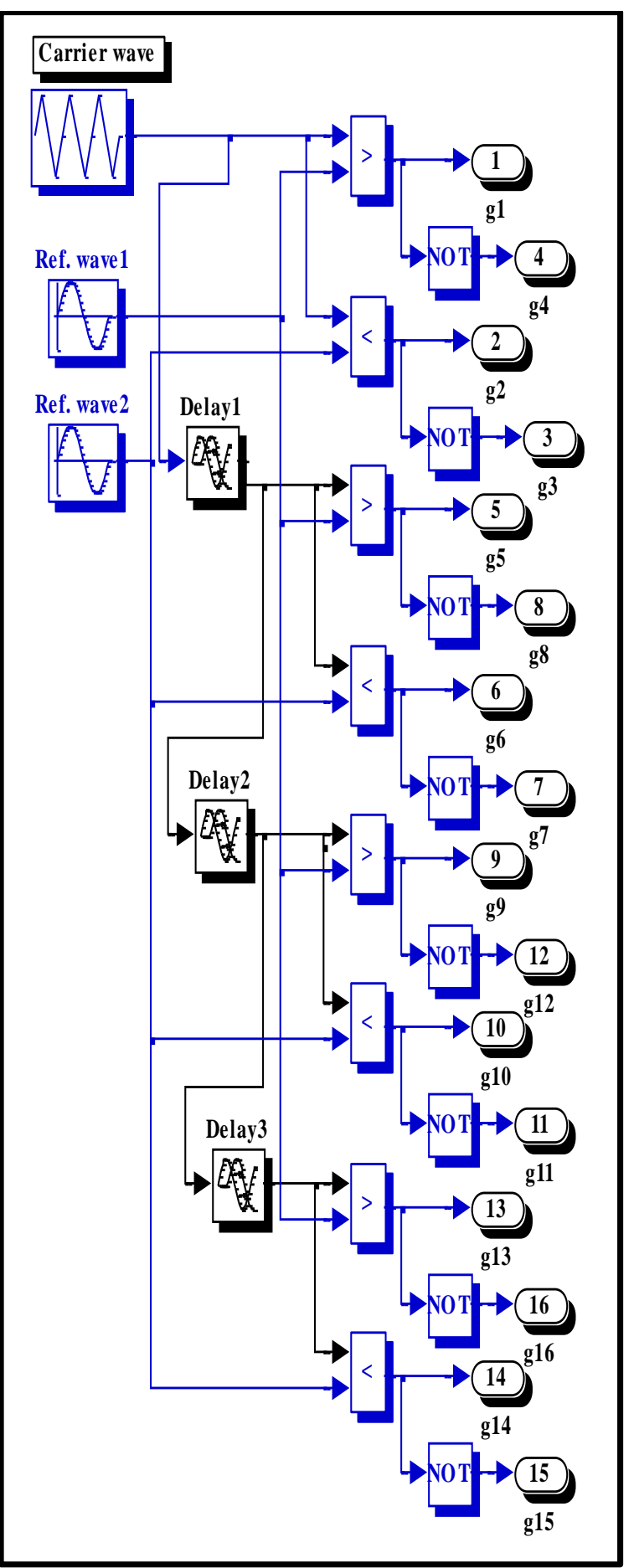

Figure 6. PS-PDM technique. 

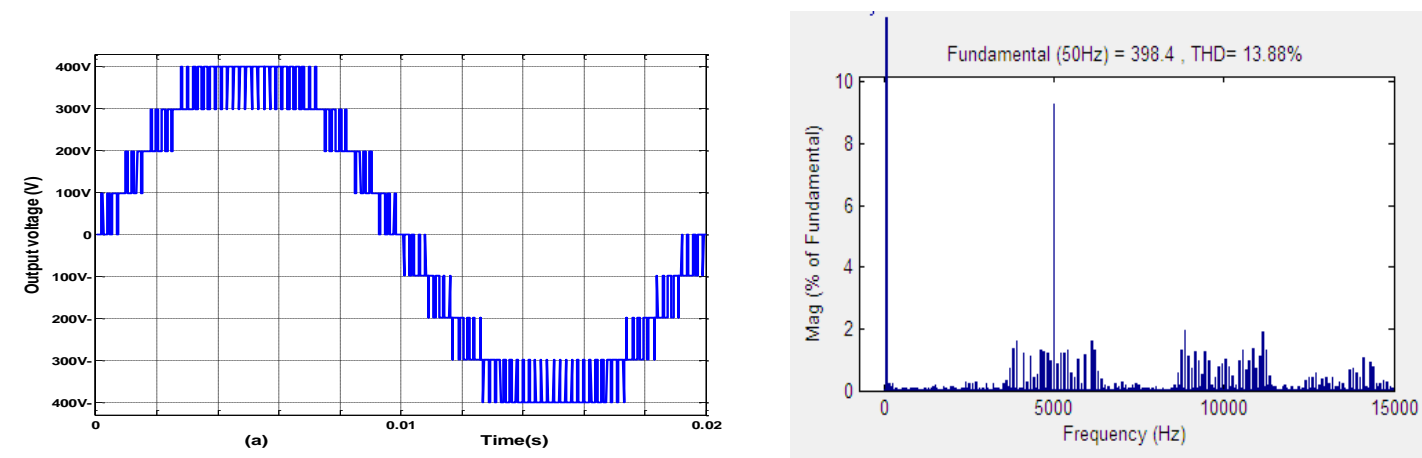

(a) PD
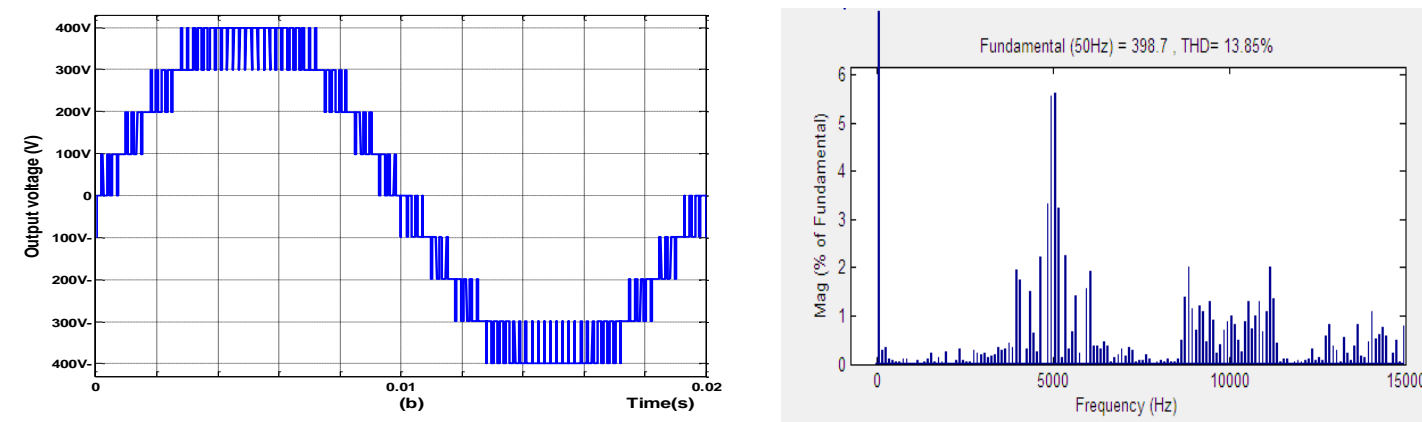

(b) POD
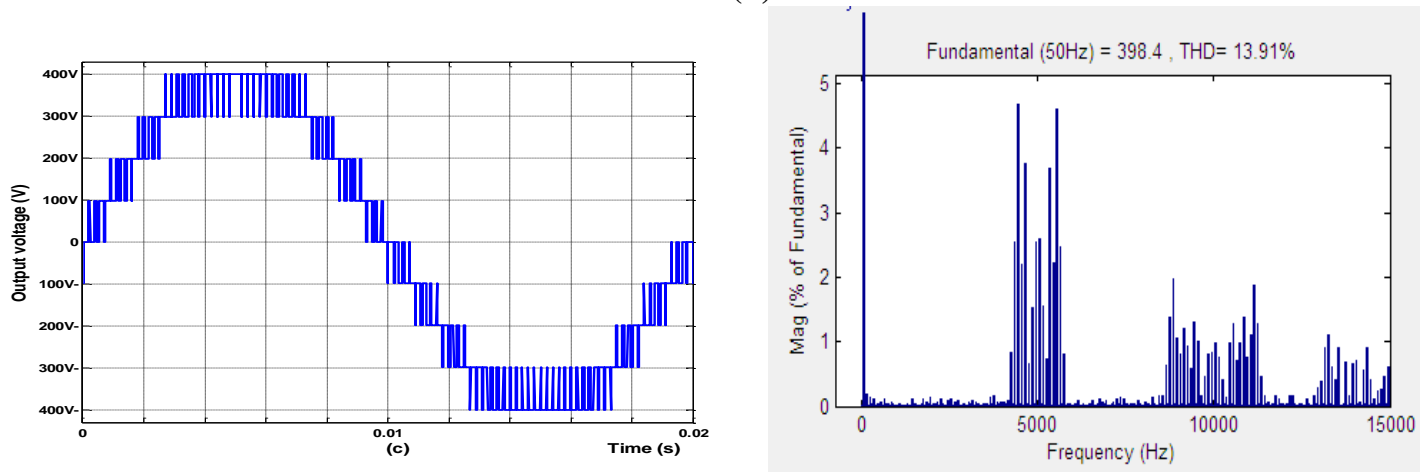

(c) APOD

Figure 7. Output voltage and the HS of nine-level DC-MLC with various MMTs: (a): PD, (b): POD, and (c): APOD. 

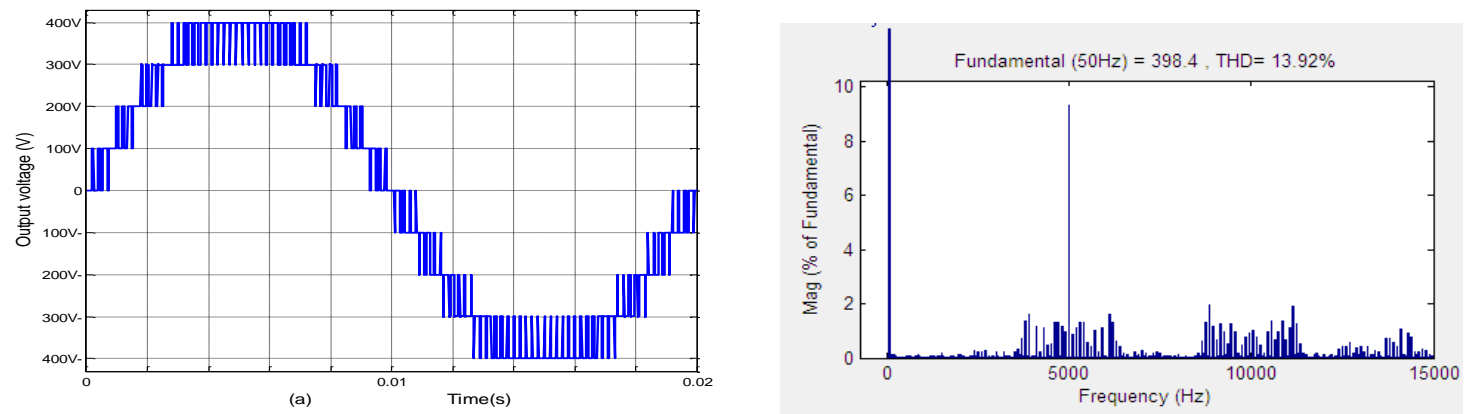

( a ) PD
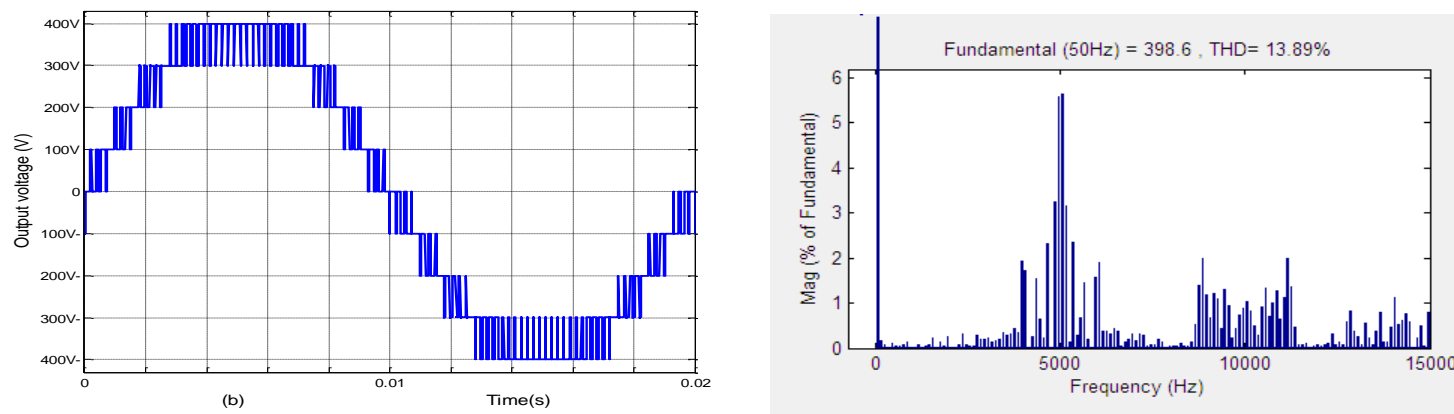

( b ) POD
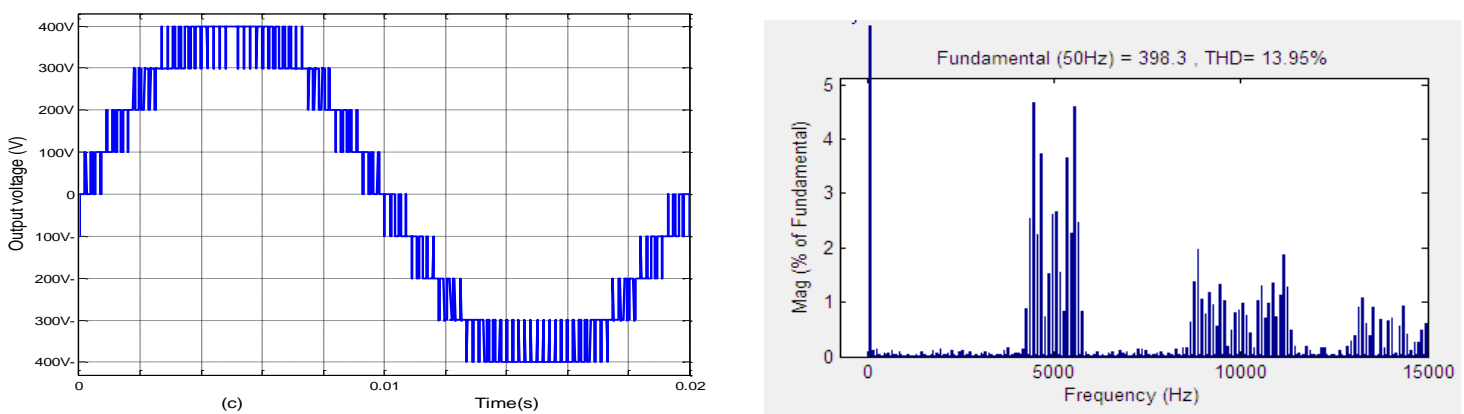

( c ) APOD
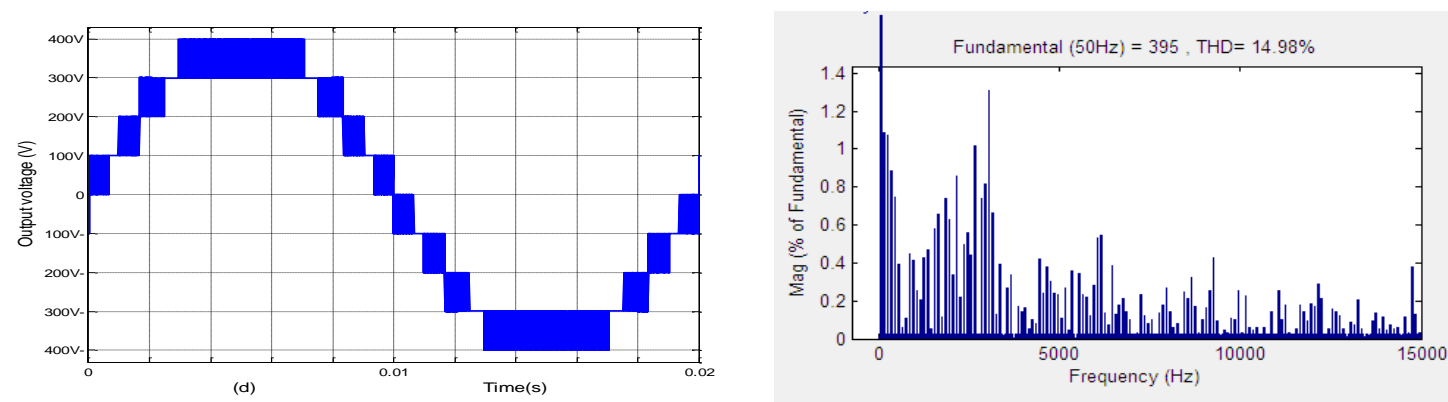

( d ) PS-PDM

Figure 8. Output voltage and the HS of nine-level CC-MLC with various MMTs: ( a ): PD, ( b ): POD, (c ): APOD, and ( d ) PS-PDM. 

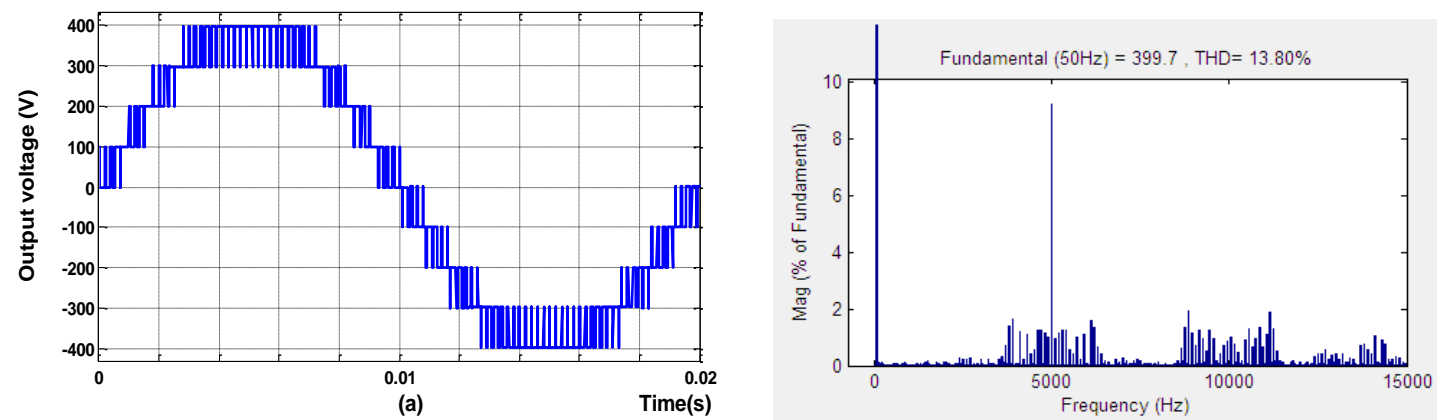

( a ) PD
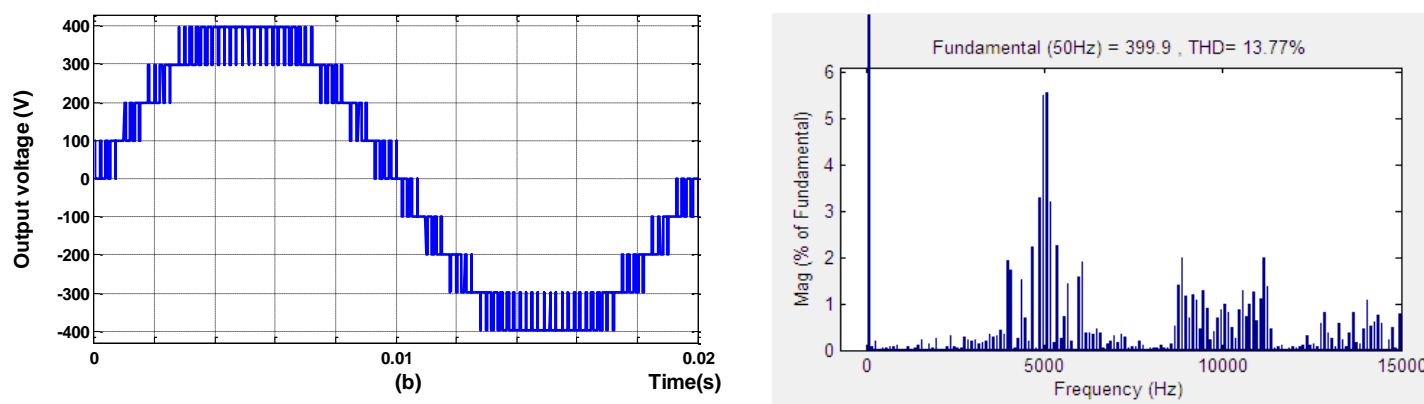

( b ) POD
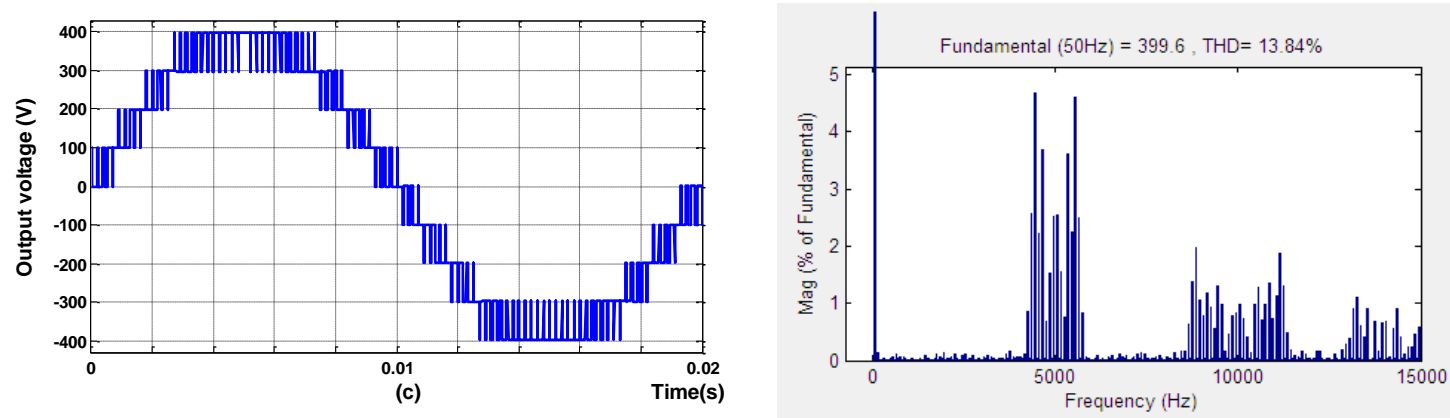

(c) APOD
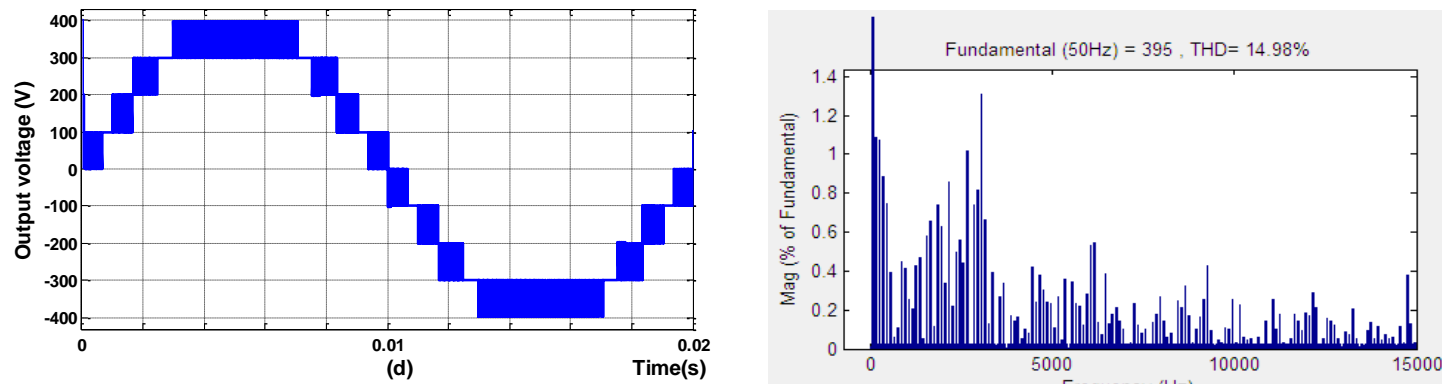

(d) PS-PDM

Figure 9. The output voltage and the HS of 9-level MS-MLC with various MMTs: (a): PD, (b): POD, ( c ): APOD, and ( d ): PS-PDM. 